\title{
Humanizing and conducive to learning: an adolescent students' perspective on the central attributes of positive relationships with teachers
}

\author{
Irene García-Moya ${ }^{1,2}$ (D) Fiona Brooks ${ }^{1,3} \cdot$ Carmen Moreno $^{2}$
}

Received: 23 May 2018 / Revised: 29 December 2018 / Accepted: 8 January 2019 /

Published online: 2 February 2019

(C) The Author(s) 2019

\begin{abstract}
The aim of this qualitative study was to identify central attributes of positive relationships with teachers from the adolescent students' perspectives that could help delineate the meaning of student-teacher connectedness while exploring to what extent its main attributes were similar or different in England and Spain. As part of the EU-funded project "Well-being among European youth: The contribution of student-teacher relationships in the secondary-school population", we conducted focus groups in England and Spain with 42 students aged 11 to 18 years. Using a bottom-up approach for thematic analysis, we identified two main attributes that were linked to positive relationships with teachers as seen by our participating students from England and Spain: humanizing relationships, in which the students are acknowledged and respected as individuals and feel understood and supported by their teachers; and relationships conducive to learning, encompassing aspects such as a perception of a genuine commitment with their learning on the part of the teachers, a positive classroom management, and teachers motivating students. This study contributes to the conceptualization of student-teacher connectedness and provides useful insights for teachers and educational professionals. In addition, the study findings pointed to the importance of power and authority dynamics in student-teacher relationships that foster or undermine connectedness, and they revealed some cross-cultural differences in the role of emotions in the class, two important aspects which deserve further attention in future research.
\end{abstract}

Keywords Student-teacher relationships · Adolescence $\cdot$ Schools $\cdot$ Connectedness · Qualitative research · Focus groups

Having a significant relationship with at least one adult in their life has been considered one of the most powerful assets for young people's health (Masten 2001). Beyond the family, teachers

Electronic supplementary material The online version of this article (https://doi.org/10.1007/s10212-01900413-z) contains supplementary material, which is available to authorized users.

Irene García-Moya

i.garcia-moya2@herts.ac.uk

Extended author information available on the last page of the article 
have been considered to be strategically located to become significant adults for their students and numerous studies have empirically demonstrated the positive impact in learning and wellbeing when a positive student-teacher relationship is established (Roorda et al. 2011; Suldo et al. 2009). For example, a rigorous meta-analysis (Roorda et al. 2011) concluded that student-teacher relationships showed significant medium to large associations with school engagement, and that the affective quality of relationships not only remained important but even became more influential for adolescent students' engagement and achievement.

However, there seems to be a lower likelihood of positive student-teacher relationships being established during the adolescent years (Reddy et al. 2003). Factors such as the reduction of the time adolescents spend with each teacher in secondary schools or the emphasis on discipline and little room for students' participation have been associated with this trend (for further discussion, see Eccles and Roeser 2009). The potential to develop student-teacher relationships with a positive impact in young people's well-being seems to be there but it is less often realized in the secondary school years (García-Moya et al. 2015; Reddy et al. 2003), which some authors have attributed to a mismatch between school characteristics and adolescent students' needs (Eccles et al. 1993). Darling et al. (2003) stated that teachers are not salient figures for most adolescents and only provide additional instrumental support, but this is in contrast with the view that teachers can become influential non-parental adults in young people's lives (Erickson et al. 2009) and studies which emphasize teachers as important sources of emotional support (Suldo et al. 2009).

Constructs such as connectedness (Townsend and McWhirter 2005) and belongingness (Baumeister and Leary 1995) have been applied to the school context to try to understand the importance of developing stable positive interactions with teachers. These constructs refer to a "pervasive drive" or "powerful need" to maintain some lasting significant interpersonal relationships characterized by positive interactions (Baumeister and Leary 1995; Townsend and McWhirter 2005). However, recent reviews (Allen et al. 2018; García-Moya et al. 2018) point out that, when applied to the school setting, these constructs have been variously defined and operationalized. Therefore, additional work is needed to achieve a clearer conceptualization of these constructs.

The understanding of student-teacher relationships can be enhanced by qualitative explorations of adolescent students' views on what makes the difference between the allegedly reduced number of teachers adolescents tend to develop meaningful relationships with and the rest of teachers they regularly interact with. When reflecting on their learning experiences, it is common that students single out specific teachers and students refer not only to instructional but also to their interpersonal skills in their descriptions of these memorable teachers (Koehler et al. 2016). Therefore, in this paper, we use the term student-teacher connectedness to refer to this special type of positive interpersonal relationship that students can develop with some of their teachers and we try to identify central attributes of such relationships.

As many other areas in psychology of education, the study of student-teacher relationships has been dominated by quantitative research, but qualitative studies have provided additional valuable insights. For example, they have been useful in voicing the perspectives of adolescents from immigrant communities (Reed and Wexler 2014) and juvenile offenders (Allen et al. 2016) or to explore in more depth adolescents' views about specific aspects, such as the perception of being known (Chhuon and Wallace 2014) and the experiences of students that nominate a teacher as a very important person in their life (Yu et al. 2018).

To contribute to expanding this body of qualitative research, the present study focuses on the understanding of experiences of connectedness with teachers (what is the difference 
between relationships with these teachers and the rest?) in a general adolescent population. Specifically, the aim of this study, which is part of the broader EU-funded project Well-being among European youth: The contribution of student-teacher relationships in the secondaryschool population, was to identify some central attributes of positive relationships with teachers that could help delineate the meaning of student-teacher connectedness from the perspective of adolescent students.

Using a cross-cultural approach for this exploration can provide additional insights to the conceptualization of student-teacher connectedness. Connectedness and other related concepts such as belongingness or relatedness have been conceptualized as fundamental human needs (Baumeister and Leary 1995; Townsend and McWhirter 2005), so it may be possible to identify key aspects in student-teacher connectedness that are common in different cultural contexts. On the other hand, educational systems' dissimilarities or cultural differences may well result in distinct features of student-teacher connectedness across countries.

To explore these aspects, the present study was conducted in England and Spain, two countries whose educational systems present some similarities but also important differences (see Appendix 1). Cultural differences have also been documented, with Mediterranean countries such as Italy or Spain being described as more collectivistic and less individualistic than England (e.g., Monks et al. 2008). Focusing on students' profiles, one of the features in UK students is their high achievement motivation and very competitive spirit, whereas the percentage of students in Spain that see themselves as ambitious and want to be the best in their class is lower than the OECD average (OECD 2017). The same source showed that Spain had the highest scores of all participating countries in students' social integration in school (OECD 2017).

\section{Methods}

\section{Participants}

Forty-two students aged 11 to 18 years, 19 from a southern county in England (UK) and 23 from a southern city in Spain, participated in this qualitative study. Potential participants were contacted via schools and via parents and were provided with an information sheet describing the aims of the study to make their informed decision on participation. Both parents' and students' consents were obtained.

In terms of the characteristics of participants' schools, some diversity was achieved in both settings. In England, participants came from mixed (50\%) and single-sex (50\%) state schools, the majority $(72.2 \%)$ from non-religious schools. In Spain, participants attended mixed schools, mostly state schools (67\%) and non-religious schools (71\%). Although the socioeconomic background of the participants was not directly assessed, proxy school and school area information indicate that participants did not come from socioeconomically disadvantaged schools.

\section{Data collection and materials}

We used focus groups, which ranged in size from 4 to 8 participants, to collect the data. Small focus groups in which participants knew each other were chosen because they favor a good rapport and facilitate that students can openly share their experiences (Braun and Clarke 2013) 
while providing each participant with enough time and opportunity to express their views. All focus groups were facilitated by the same researcher, using the topic guide in Appendix 2.

The focus groups started with broad open questions and later asked the students to focus their accounts about the teachers they felt closer to or more connected with. At the end, participants were always asked for other aspects that they felt were important but had not been covered and each participant was individually asked to provide a summary by completing the sentence: "Student-teacher relationships would be better if..." While keeping with that general structure, the guide was used flexibly, with follow-up questions to further probe on the views expressed by the participants being prioritized over covering each of the examples of questions in the guide. Each focus group lasted approximately 50 minutes.

\section{Data analysis}

Focus groups were recorded and transcribed verbatim. Thematic analysis (Braun and Clarke 2013) was used to identify meaningful themes in data and to obtain an organized and rich description of adolescents' views about the key attributes of positive relationships with teachers. The themes were generated from the data using a bottom-up data-driven approach. We adopted this approach to maximize investigative depth and illuminative fertility (Shank and Villella 2004); the rationale was that applying an a priori theoretical framework was likely to limit the scope of analyses, directing them in pre-specified directions and reducing their sensitivity to new insights. The analyses included the six phases usually recommended for rigorous thematic analysis (see, e.g., Clarke et al. 2015). In short, after several readings of the transcripts to familiarize with the data, a researcher proceeded with coding the transcriptions using an inductive iterative process. Initial and higher-level coding were discussed with another researcher at different points of the process as part of an interactive coding refining process that, after recursive phases of mapping and reviewing the candidate themes fit with the data, concluded with the definition of the themes and subthemes used to structure writing. The other researcher acts as an additional analytic auditor. Thanks to the ongoing discussion of the coding and refining steps among the researchers and repeatedly going back to the data to check provisional interpretations' sensitivity in capturing participants' views, this strategy has several benefits: an in-depth engagement with the data, increased openness to alternative interpretations and to the identification of complexities and inconsistencies in the data, and a reduced risk of uncritically imposing the researcher's implicit ideas on the data.

For presenting the study findings, a narrative approach is used in which main themes are described and illustrated with actual quotes selected from the focus groups, paying attention to a balance between selecting most clear and vivid examples with using extracts from as many different participants as possible (Braun and Clarke 2013). Adaptations made to the quotes presented in the "Results" section include using pseudonyms instead of the participants' real names and deleting repetitions, hesitations, or fillers ("like," "and so," etc.) that did not inform interpretation to facilitate reading. In addition, although material was analyzed in its original language, we present extracts from Spain translated into English to make the results accessible to non-Spanish speakers. Untranslated quotes from focus groups in Spain are available in Appendix 3. 


\section{Results}

The interpretation of initial coding and higher-level coding resulted in the identification of two broad themes in adolescents' descriptions of positive relationships with their teachers: humanizing relationships and relationships conducive to learning.

\section{Humanizing relationships}

The theme humanizing relationships groups different elements that incorporate a personal dimension into student-teacher interactions (Table 1 describes this theme and its subthemes). Humanizing relationships can be defined as those that offer a departure from transactional student and teacher roles by paying attention to the person beyond the learner, with salient features including an individualized kind of personal interaction, increased mutual understanding, and the availability of support that is responsive to the student's needs.

Respectful and individualized personal interaction Students expressed a need to be visible and receive individual attention in order to connect with a teacher, but frequently encountered a whole-class approach to teaching:

-Ophelia: I think they're so busy teaching everyone else that they like don't notice you, and they just like notice everyone else that's listening.

-Betty: I think as a whole they're trying to focus on the whole class rather than individual people.

(England, 13-14 years)

Students resisted that view of them as a collective anonymous mass and wanted their teachers to know them as individuals, with aspects such as teachers addressing them by name, being

Table 1 Description of the theme humanizing relationships and its subthemes

Humanizing relationships

The students feel they are known and respected as individuals and that teachers interact with them at a personal level, which in turn allows for them to see a different side of their teachers. There is a personal or humanizing dimension present in student-teacher interactions, rather than relationships being neutral and unidimensional, in the sense of restricted to an exclusive subject- or grade-centered focus.

Respectful and individualized personal interaction:

The student describes personal positive interactions with the teacher in which the human side of the teacher is shown and the student feels they are known and respected as persons by the teacher.

Empathy and perspective taking:

The teacher is perceived as sympathetic and understanding in their interaction with the student and more broadly they are able to see things from the students' perspective.

Support:

The teacher is seen as an approachable person, willing to help the student if they needed it with academic and non-academic problems. 
able to recognize their work, or describing their individual level in a class or their past work in some detail in events such as parent evenings being considered of fundamental importance:

-Anna: Well I also think like when we have parent's evening you can really tell which teachers know you personally and the ones that don't care about like, they just kind of say 'oh you're working at this level' and that's it, but others know like what work you did last week...

-Irene: Yeah. Like how you're doing in class.

-Anna: ...it kind of makes you feel more close to them and yeah.

-Irene: Some, yes, like one of our teachers literally goes 'oh sorry, who are you again?'

And it's like you've taught us since September, you know, the least you could do is learn our names because that's a thing, that's like the first thing you do when you meet a person is you go 'oh what's your name?' And it's polite and it's like just, it's not very, you just want to connect with the teacher and when they don't even know your name how can you do that?

(England, 15-16 years)

According to the students, some teachers made an effort to engage in more personal interactions, even creating specific spaces to get to know all their students better. Magdalena (Spain, 15-16 years, translated) talked about a teacher of her who organized regular assemblies in the class: "to know his students, in like he asks questions or we talk about a bit of everything, so that he knows the students and we get on well with the teacher. I think that, if we did that with some teachers, being in class would be better, that the relationship with teachers would be different if things were done like that.". However, other teachers were perceived as only concerned for academic aspects, such as complying with their lesson plan or the students' academic achievement in their subject.

Being able to see the human face of the teacher was an important aspect for a more personalized style of interaction. From the students' accounts, it would appear that the person the teacher is gets hidden by a particular way of enacting teacher-student interactions that is formal and disconnected. Even relatively small humanized interactions that revealed a more personal side of the teacher made the students feel more connected. For example, some teachers create opportunities to see "a different side" of the teacher when they use some time at the beginning or end of the class to chat with the students informally, use sense of humor, or share personal anecdotes during their lessons:

Abel (Spain, 17-18 years, translated): Yeah, and to me a good teacher is someone who translates their subject into life, like their life. For example, a teacher that along with their subject tells you lots of anecdotes that they have lived, that have happened to them, and with that type of teachers is with the ones that I would have more trust, because since they have brought their life closer to me by talking about it in class, then I would dare to tell them things about mine.

Henry (England, 14 years): I think that when teachers have a joke with you, that makes them a lot better. Instead of just being serious all the time, if they can have a laugh with you, then you give them more respect for that and then when they tell you to do your work you will. 
When asked about the importance of teachers sharing anecdotes or making jokes, some participants linked this to feeling closer to teachers, as opposed to other teachers' behavior that was perceived as active efforts to keep distances with students:

-Lydia: Because it makes us feel...

-Antonio: Better.

-Lydia: Yeah.

-Paco: Similar to them.

-Diego: More comfortable [...] Like closer, as if we were friends with them, that they even tell us their things.

-Facilitator: Ok, that you feel that you tell them a bit but they also tell you?

-Diego: Yeah.

-Clara: Of course we know that they are our teachers, that we have to behave well with them and all that, but there is no need to start to...that some teachers go too far!

-Facilitator: How do they go too far? Tell me a bit about it because I don't know very well...

-Clara: For example, last year, when one teacher entered, we all had to stand up and then sit down, that it seemed...

-Antonio: True, yeah, and this year we also have to do it.

-Clara: ... that it seems as if we are soldiers or something like that!

(Spain, 13-14 years, translated)

As with rituals used by the teachers to assert an authority position, some imposed norms had a de-personalizing effect and negatively affected the relationship with teachers. In several of the younger groups, very strong views were expressed about teachers' rules that established embodied control, such as toilet rules (some students had to ask for a pass to go to the toilet, were allowed to go only once or after some minimum time after a break had passed, etc.). Students saw such embodied control as an unfair and unreasonable exercise of power and explained that those rules made them feel "controlled" and "persecuted". Similarly, teachers' disregard of students' opinions put in jeopardy the respectful kind of interaction linked to humanizing relationships that foster connectedness. Clara (13-14 years, Spain, translated) talked about a teacher "who says that the students' opinion is worthless, says that students have been given much freedom and that it should not be like that", with the rest of participants in the group expressing their unease with this position.

In contrast, out-of-the-class activities, such as extracurricular activities and school trips, were seen as providing a space in which roles become more relaxed and horizontal, which made it possible to overcome some of the boundaries experienced in the class.

Rosalía (Spain, 15-16 years, translated): Recently, we came back from the end-of-theyear trip and three teachers went that are known as the corporals, the colonels [laughs] And when we left we said 'we are going to have a bad time with these teachers because they are going to be very strict with us', but when we arrived there, it was better than with the ones we consider the best, you know? And it was as if we had known a different side of the teachers and we now know that they are not like that, that they are acting tough! 
Empathy and perspective taking Another aspect highly valued by the students was a teacher's ability to see things from the students' perspective and a general degree of empathy with each student's situation.

On a general level, students sometimes had the impression that teachers understood them simply from a teacher's discourse in presenting the subject or a way to organize the class that was sensitive to students' preferences or feelings:

Daniella (England, 15-16 years): But also when they understand like us. If it's a Monday morning and it's the first lesson, we're all tired, they're like 'I understand it's Monday morning but come on let's...', like they understand. They sympathise with you.

A main focus of students' discussion under this theme was whether teachers were able to see things from the students' perspective when they recognized that a subject may be difficult and that students may struggle to understand something. Feelings of disconnection were often expressed as resulting from teachers who failed to consider that and showed a certain degree of fixation in their perception of the content or a particular way to do or explain things that they used for all the students:

-Rosalía: 'Because it's logical!' How logical? It is logical for you! [laughs]

-Ángela: That's it! It is logical for you who studied that degree, for me who I'm hearing it for the first time, I don't get it.

-Magdalena: Like they are saying it is very easy.

-Rosalía: 'Logically', 'Logically'. Yeah, sure, logically...

-Ángela: And also, like in two plus two equals four. And right it is logical for you because you studied Maths, but I may not understand it, then you have to spend more time in that two plus two, you know? That they take more time... that they don't take everything for granted.

-Magdalena: Or when they explain that thing you don't understand, that they try to use a different way to explain it to you. That they explain it again in the same way and you may not understand it that way, but they don't want to try another way of explaining it, and I think they should try a different way to explain that to you, so that you understand.

(Spain, 15-16 years, translated)

The way teachers interpreted students' behavior was also mentioned as a source of misunderstandings. On occasions, teachers were perceived as self-centered in their perspective or interpretations and students felt unfairly judged, with the subsequent negative effect in relationships:

Linda (England, 11 years): Well, my teacher is nice and I like her very much and she understands my class, but there's one teaching assistant that doesn't really understand any of the children, and she just thinks it's all about herself, so whenever a student says something like an accident, she won't forgive them, she'll be mad at them [...] She doesn't really understand them.

Students also talked about empathy at a broader level, as a desire that teachers were understanding with students' situations outside of the specific subject or even outside school:

Ángela (Spain, 15-16 years, translated): That also annoys me so much! They set a lot of homework and you say you have an exam tomorrow and they say 'I don't care'. And it 
is like 'that I don't have you subject only!, do you know it?', I have many others and I have a life beyond your subject, understand me a little bit!

Felicity (England, 17-18 years): From my experience sometimes things can get stressful and I need extra time for work and sometimes they're not willing to give me extra time and it's kind of annoying because it's like they don't understand how much time I have, they don't understand I have other subjects and other pieces of coursework. So it can get quite frustrating because they kind of like to think that their subject is the most important, when we have a lot of other subjects as well.

Finally, some students talked specifically about teachers' behavior in response to emotional displays. Students in each of the focus groups conducted in Spain shared experiences in which disconnectedness with specific teachers had resulted from having some emotional problems to which teachers had not responded in a sensitive manner:

-Rosalía: Yeah, there are some who ask you to stand up when your face is full of tears. You are feeling bad and ask them permission to go to the toilet and they won't let you, they say 'wait for a while'.

-Magdalena: [half laughing] It seems that they like it or that they enjoy seeing you sad.

(Spain, 15-16 years, translated)

These situations seriously damaged the relationship with the teacher and had a negative effect in the students' well-being. Ander (Spain, 17-18 years, translated) told that he was suffering an anxiety attack during a class and left the room, and his teacher criticized his behavior and warned him afterwards that he may be penalized, and added "[...] and, well, the truth is that I ignored that completely, but well, it is there. Up to her". Similarly, Clara (Spain, 13-14 years, translated) mentioned a situation in which she had a problem at home and started crying during a lesson. She was told to stop crying because that was "good for nothing" and explained how bad it made her feel: "[...] I felt even worse because I was having a bad time and in addition to that they tell you something else which makes you sink even more, so you feel yet even worse". Clara completed the sentence "relationships with teachers would be better if..." precisely underlining the importance of emotions for her:

To me it would be better if they showed an interest and cared about your feelings a little bit, and how you feel, and they would leave aside to some extent the student-teacher relationship, and acted more a bit like a psychologist and they understand, they can help you and all that because sometimes I don't know who to go to.

Students in England did not share personal situations like the ones above. Their only explicit reference to open emotional displays was a brief discussion about a classmate with autism who sometimes burst into tears in class and how some teachers reacted to this better than others (sending the student to the library or referring them to the student support service was seen by the participants as a good response to that situation). It is difficult to know whether these situations are less prevalent in England (either because students tend not to show their emotions in class or because, if they do, teachers respond in a way considered appropriate 
by the students) or whether participants simply did not share these experiences during the focus group sessions. Still, it did not seem that students in England considered emotions unimportant. For instance, Amy (England, 13 years) emphasized the importance of paying more attention to the emotional well-being of the students:

Student-teacher relationships would be better if the teachers actually showed a proper interest in the students, like emotional well-being, because right now the teachers don't really do that, like they don't really care about your emotional well-being that much, or it doesn't seem like it, and it just seems like they just bypass you and the only thing they really care about is if you're matching up to your targets and getting good grades, and then they don't need to worry about anything else because they think they're doing their job. I think it would be better if they showed an interest into the students' emotional well-being.

Support Frequently entangled with teachers' understanding of students' needs, the third subtheme of humanizing relationships was support, which was commonly mentioned as part of positive relationships with teachers:

Holly (England, 15-16 years): It's like you can get like a one-on-one relationship with them and they help you.

Alfonso (Spain, 15-16 years, translated): It is like a psychologist teacher. That they help us...

Students would like their teachers to help them when they need it and in general they described better relationships with those teachers that were seen as "approachable". With that term, students alluded to a perception that teachers would be willing to listen to them and help them if they asked them for help or advice:

Ian (England, 17-18 years): When we're talking about like go and tell the teachers, going to them and asking for help, some teachers are not really approachable in that way. Like if you're uncomfortable about talking to them, like you just feel stupid sometimes. I just think that you need like a more approachable teacher that would relate to you more, want to speak to you.

This view of teachers as approachable figures was sometimes encouraged by teachers explicitly communicating their willingness to help to their students:

Anna (England, 15-16 years): she's always like 'come and ask me if you need help or anything like that'.

whereas in other occasions students inferred it from behaviors such as whether teachers initiated an interaction when they perceived the students may need help:

-Paloma: The thing is that I think that our trust is won by the teachers that notice everything because there are teachers who may see someone with a face that shows they are a bit dizzy or whatever and they ask, they stop the class 'are you all right?', or they see someone with a weird face 'let's see, you must have not understood this', etc. and like they pay attention to each student and it seems as if you have them closer [...] but that sometimes a person is feeling really bad or is not understanding a thing and they 
have a very weird face and there are some teachers who realize and stop the class and others who don't care... because I'm sure they have realized, because I sometimes have that face that I'm not understanding a thing and the teacher looks at me and continues with the class. [laughter]

-Facilitator: Does that happen to the rest of you? Do you have that feeling?

-Mila: Yeah.

-Pedro: Yes, the one who pays attention to the details and cares about you and that is fundamental.

(Spain, 17-18 years, translated)

It must be noted that students tended to make a distinction between academic and nonacademic problems. There was more consensus in teachers being the figure to go to for academic problems, but some students preferred keeping personal problems to themselves, telling friends or parents. Some students draw a clear line between school and private life and although they would approach teachers they had a good relationship with for academic or school-related problems, they felt that personal problems were out of limits. Gerard (England, 17-18 years) explained that you could not really approach a teacher with a personal problem because that was not their role: "They're paid to teach you, not to do anything else".

In contrast, although in general students' accounts implied that confiding a personal problem required a closer and more trusting relationship, some participants said they could approach specific teachers they felt closer to:

-Magdalena: Well, if you trust a teacher a lot, like there is a teacher here, the technology teacher, that builds trust for you to tell him your problem.

-Alfonso: Definitively.

-Magdalena: And I think that a teacher like that who you trust and who helps you, I would tell them, yes. [...] Because, I don't know, when you feel bad, as Alfonso said before, they approach you and ask you and that, others see you are bad and ignore you. That's is what I mean.

(Spain, 15-16 years, translated)

Table 2 Description of the theme relationships conducive to learning and its subthemes

Relationships conducive to learning

The teacher succeeds in facilitating learning, which reinforces connectedness with that teacher.

Commitment to teaching:

The teacher is perceived as showing a genuine concern for the student's learning and making actual efforts to facilitate learning, as shown by their teaching style or availability to offer extra support or resources.

Management of the class:

The teacher sets the necessary limits that facilitate an appropriate environment for learning. It does so with authoritativeness rather than in an authoritarian way.

Teacher motivating students for learning:

The teacher is seen as able to promote learning thanks to their teaching style and their passion and enthusiasm about the subject. 


\section{Relationships conducive to learning}

Along or frequently intertwined with aspects of a humanizing relationship, students elaborated on the importance of relationships conducive to learning (Table 2 describes this theme and its subthemes) and linked this to how connected they felt with their teachers. Relationships conducive to learning can be defined as those fostering a learning-enhancing classroom environment, with salient features including the teacher's genuine commitment with their job, effective and nurturing classroom management style, and motivating skills.

Commitment to teaching Students emphasized the importance of teachers genuinely caring about their students' learning; when they perceived that teachers made an effort to make them achieve the most they could, it was easier to connect with those teachers:

-Irene: I think what it is, it's you get the effect from some teachers that they are just there because it's their job and, you know, they get paid for it.

-Holly: Like they have to be there.

-Irene: But other teachers, it's not only their job, you know, they're in it full head and heart and...

-Holly: They genuinely want to see you do well.

(England, 15-16 years)

Teachers that went out of their way to prepare the lessons and facilitate students' learning were perceived as teachers who cared about the students and described in contrast with a group of teachers the students did not connect with because theirs was what Antony (England, 14 years) described as a type of "lazy teaching", which generates disengagement in the student due to a lack of planning and effort and of genuine concern for the students' learning, motivation, or actual understanding of the subject:

-Mila: It also shows you that he has prepared it and that we truly matter to him, doesn't it? Because maybe a subject like in history or biology that the teacher comes at the first hour of the day with theory and they read the book and you think 'they could have prepared something', an activity or something like that, to wake us up and to move us and motivate us, you know? But we are with the same all the time and it seems that they have prepared nothing, and that they don't care about us.

-Ander: That a teacher is a teacher, they are not superior people. In other words, if we come to school to work, so do they, right? They have to make a living by doing their work well.

(Spain, 17-18 years, translated)

Although Mila also mentions motivation in the preceding extract, there is an emphasis on whether or not the teacher has prepared the lesson and the message that gives the student about the teacher's commitment with their learning. That is seen at the beginning and end of her intervention, and it is reinforced by Ander's and by the interventions that followed the ones reproduced here. Finding specific teaching styles motivating was another related but distinctly discussed element in students' accounts (see the subtheme "Teacher motivating students for learning" also in this subsection). 
Management of the class In the students' opinion, teachers also needed to show a good management of the class: setting limits and having control of the situation, so that a good learning environment is achieved, and students can concentrate and pay attention. Students stressed the importance that this element was balanced with keeping a positive climate and a caring relationship:

-Betty: I like teachers that are, like they're strict enough to tell people off when they're messing around lots, so that you can concentrate, but I like teachers that can have a bit of fun as well, and they can have a joke with the people they're teaching, instead of being like really...

-Amy: Regimented?

-Betty: Yeah, the whole time.

(England, 12-13 years)

Anna (England, 15-16 years) described a teacher she felt particularly connected to as being "in the middle":

Like she can still control the class and people have respect for her but she's friendly and I could always approach her and ask her, and the fact that she allows you to do extra work and marks it and everything. Like she's always like 'come and ask me if you need help'.

In addition to facilitating learning, an effective and positive management of the class was also emphasized as generating respect toward the teacher as an authoritative figure. Authoritarian ways to keep order or a rigid control imposed to students, in contrast, undermined a positive climate and the respect toward the teacher.

-Ander: A teacher...I think it is a person who you respect and admire. It is not a dictator teacher, who is a person you hate, you don't get along with and you are afraid of.

-Mila: It's what I said before, that I have respect for the philosophy teacher for example, I respect him because of that, it is like some trust that I cannot fail him, but to that teacher is not respect, it is fear, of how she'll respond to me, what she'll think, that she is going to think I'm like that and besides it can affect my marks, then you see them differently.

(Spain, 17-18 years, translated)

Teacher motivating students for learning Finally, the ability to motivate the students and the teachers' passion for their subject also seemed to make the difference for some students when it came to the teachers they had better relationships with:

Salvador (Spain, 17-18 years, translated): I was going to say that it's not only trust, but that they motivate you in the class, that to me philosophy is a subject that there is no way to come to grips with it but with this teacher you have a laugh in class and that, and I pay attention, but any other teacher teaches me that subject and I shoot myself 
[laughing]. I don't know, that the subject is not, but that teacher is very good, in addition to the trust and all that, that he motivates you to go to class.

A certain type of teaching style, usually more interactive, combining different types of activities, and trying to present things in a way that connects with students' interests, was linked to motivation:

-Paco: That they made the lessons more fun, that they did not always do the same thing, because there are teachers who always do the same, which is teaching the lesson and teaching the lesson and it is boring.

-Lydia: I think they know perfectly well the thing that we find more fun, and the things that we find fun make us pay more attention and listen more, then I think they could do it.

(Spain, 13-14 years, translated)

Antony (England, 14 years), for example, felt that the quality of his relationships with teachers was very dependent on this more "interactive" kind of teaching:

I've got like all different teachers for different lessons, so it just depends on what lesson it is, I'd say most I might have like a bad relationship, but that's because their lesson is not enjoyable and interactive, but the ones that are engaging, I have a good relationship with them because I respect them.

At a different point of the discussion, he explained that this "interactive style" was what separated some teachers from what he called "stereotypical teachers": "moody and your lessons aren't fun, yeah, being boring lessons, just like in silence [...]".

\section{Discussion}

The aim of this qualitative study was to help delineating the meaning of student-teacher connectedness by identifying central attributes of positive relationships with teachers from adolescent students' perspectives while exploring to what extent these were similar or different in England and Spain.

Importantly, we found more commonalities than distinctness in the students' experiences in England and Spain. Despite the cultural differences and dissimilarities between educational systems, students from both countries tended to single out a few teachers they felt closer to and described differences between them and the rest of their teachers in similar terms. Our findings confirm that support is an essential element of positive student-teacher relationships (e.g., Klem and Connell 2004) while directing our attention to empathy and affective interpersonal interactions as other fundamental (not so extensively examined) aspects.

To our knowledge, there is a lack of qualitative studies that explore cross-cultural commonalities and differences in the meanings of connectedness with teachers for adolescent students. There is an ongoing debate on whether measures of connectedness can be invariant across countries or there are some culturally specific aspects (Karcher and Lee 2002; Sass et al. 2011). Our findings support the idea that connectedness with teachers is a relevant construct 
and shares core attributes in England and Spain. Next, we elaborate more about salient common features, while pointing to some slight differences across countries also captured in our study.

In both England and Spain, students' accounts suggested that supporting learning and supporting the student as a person (what we called the humanizing and conducive to learning elements of relationships) should be seen as two closely intertwined aspects of teaching. Individualized interpersonal interactions were central in experiences of connectedness with teachers, which suggests a need to revise the assumption that professionalism as a teacher is to be characterized as a neutral, de-personalized style of interactions with students. A tension can be generated between the general view that professional relationships must be of a formal or impersonal nature and the importance that a teacher cultivates personal relationships with students (Carr 2005). Our findings question the value of a formal or neutral style of interactions as a professional standard that teachers should strive for. Instead, interactions which humanize teachers and students (including informal conversations about hobbies, sharing personal anecdotes, joking, etc.) favor connectedness.

Our exploration of students' perspectives also provided a more in-depth understanding of how day-to-day dynamics shape student-teacher relationships in ways that favor or undermine connectedness. Students' basic need to be acknowledged in their identity and agency as individuals was not always met in their interactions with teachers, which is consistent with the stage-environment fit theory that the teacher control or the reduced opportunities for participation in decision-making that are frequent in secondary schools do not fit well with adolescents' needs (Eccles et al. 1993). Our findings allowed describing some dynamics that may contribute to this mismatch and undermine student-teacher connectedness in further detail. Marked vertical relationships, with the teacher adopting a leader role and making decisions while students are seen as a passive group of recipients of the teacher's performance or teaching approaches which subsume the individuality of the students in the anonymous collective mass of the whole class, were examples of such dynamics.

Interestingly, our study also revealed the salience of classroom power dynamics in students' descriptions of student-teacher relationships. Rituals to mark distances and roughly assert authority on the part of the teacher generated feelings of disconnection, with enactment of forms of power such as force or coercion (for a detailed description of forms of power, see Wrong 2009) being strongly resisted by students, who perceived coercive authority as a form of imposed control. In contrast, students respected teachers who used open communication and a more personalized interaction that acknowledged and valued their identities and opinions.

Considering this finding, efforts should be done to overcome the limited view that authority is possessed by the teacher and that rigid rules and disciplinary sanctions are the tools to enforce it. Teachers have been found to believe that it is their role to take the lead while students need to be disciplined, leading to a preference for dominant behaviors (Zhu 2013). Instead, more attention needs to be paid to personal relationships and teacher personal attributes as a basis for authority, aspects which have traditionally been neglected in our schools (Macleod et al. 2012). Our findings are also in line with a view of teachers' authority as resulting from their interactions with students, in which authority is continuously negotiated and granted through class interactions (Pirrie and Rafanell 2017).

It must also be noted that the student's views on the need for teachers to respect students' individual identities and autonomy do not negate the importance of the need for the setting of limits, as shown by the students' positive appreciation of teachers' good class management skills. Nevertheless, paralleling findings from studies on authoritative parenting, "being firm 
and consistent in establishing and enforcing guidelines and limits" (Steinberg 2001, p. 7) seems to be appreciated by adolescent students in relationships with teachers where warmth and nurturance create a positive emotional context.

Finally, emotional aspects precisely also had an important impact in the dynamics that foster or undermine student-teacher connectedness. Students' accounts stressed the importance of teachers paying attention to their emotional well-being and being empathetic with their emotions, which supports the view that emotions are important for building a positive climate of relationships in the class (see Garner 2010, for a review). However, some students in Spain (but not in England) described situations where teachers reacted negatively or asked them to supress their emotional displays as important sources of disconnection.

Emotion expression is moderated by culturally situated display rules on the degree of and type of emotional expression which is acceptable in different social situations and settings (Mesquita and Frijda 1992). In addition, teachers can vary in the extent to which they express and allow emotions to be expressed in their class: some treat emotions as central, whereas others try to create affectively neutral classrooms (Garner 2010). The situations described by Spanish students may arise from a conflict between teachers' and students' views on display rules in the class, but such conflicts were not spontaneously described by the students in England. The Spanish culture may be more permissive with showing and talking about emotions, but whether this results in a higher likelihood of dissonance with teachers that try to make the class an emotionally neutral environment in Spain or whether, for example, it translates in a higher likelihood of students from Spain sharing these personal experiences in the focus groups is difficult to say. Given the importance of emotional aspects in both countries and the growing organizational literature linking emotion-rule dissonance with decreased wellbeing (Hülsheger and Schewe 2011), this is an interesting finding that deserves further examination in future research.

One limitation of this study is that it relies on a convenience sample of adolescents, although this sample covered the key elements of diversity connected with the study aims (age and cultural setting). Examining other potential sources of diversity can complement this study. For example, qualitative studies using purposive sampling can explore connectedness experiences for students attending specific types of school of theoretical interest, such as disadvantaged schools or schools where caring relationships feature prominently in the school vision. It must also be noted that the study aim is not statistical generalization but getting a richer understanding of positive student-teacher relationships and the phenomenon of studentteacher connectedness from the student's perspective. This study findings can also provide a useful starting point for quantitative research interested in quantifying the frequency of the identified experiences or the size of potential individual differences in representative samples of adolescent students.

\section{Concluding remarks and future directions}

This small-scale study contributes to expanding the current understanding and conceptualization of student-teacher connectedness. By listening to adolescent students' voices in two different countries, we were able to identify several attributes for the characterization of this concept. Although further research may potentially identify additional aspects of studentteacher connectedness, based on our participants' views, a definition of this construct should emphasize a humanizing kind of personalized teacher-student interaction, including the 
student's perception that teachers notice and respect them as an individual, are sympathetic and can see things from the student's perspective, and act as supportive figures responsive to the student's needs. Furthermore, student-teacher connectedness was linked to a teacher's ability to build a learning-enhancing classroom environment, with key aspects for our participants including the teacher's genuine commitment to their job, effective and nurturing management of the class, and motivating skills.

In our view, the fact that those were common elements in students from two different countries can be seen as an indication of their centrality, which does not negate the possibility that connectedness experiences may also differ from student to student at a finer grain. In fact, our results about the role of emotions in the class and the kind of support needs students voiced provide some indication of this between-student variability, an aspect which deserves further examination.

This study also provides useful practical implications for teachers and educational professionals that have been presented along with the discussion of findings. To summarize, there is a need to stress the importance of the humanizing aspects of student-teacher relationships and to challenge views of professionalism that can lead secondary teachers to approach relationships with students from a standpoint of professional and emotional distance (see also Carr 2005; Hargreaves 2000). Similarly, it is fundamental to work toward a more dialogical and negotiated view of authority, since the coercive and dominant behaviors some teachers use tend to undermine rather than reinforce their authority in the eyes of the students. Both aspects should be addressed in initial and continuous teacher training.

Finally, the in-depth exploration and little design constraints in this study proved useful in revealing important non-anticipated aspects. This opens the door to additional lines for future research, such as exploring the extent to which teachers and students have shared or discrepant views about classroom power-authority dynamics and emotion expression, and examining continuities and discontinuities between adolescents' relationships with their parents and with their teachers.

Funding This project has received funding from the European Union's Horizon 2020 research and innovation program under the Marie Sklodowska-Curie grant agreement No 657482. Dr. Irene García-Moya has received financial support through the Postdoctoral Junior Leader Fellowship Programme from "la Caixa" Banking Foundation (LCF/BQ/LR18/11640009).

\section{Compliance with ethical standards}

Ethical approval was obtained from the relevant bodies, specifically the University of Hertfordshire Ethics Committee for Health and Human Sciences (HSK/SF/UH/02456) and the Comité Coordinador de Ética de la Investigación Biomédica de Andalucía (PEIBA: 0188-N-17).

Open Access This article is distributed under the terms of the Creative Commons Attribution 4.0 International License (http://creativecommons.org/licenses/by/4.0/), which permits unrestricted use, distribution, and reproduction in any medium, provided you give appropriate credit to the original author(s) and the source, provide a link to the Creative Commons license, and indicate if changes were made.

Publisher's note Springer Nature remains neutral with regard to jurisdictional claims in published maps and institutional affiliations. 


\section{References}

Allen, M. L., Rosas-Lee, M., Ortega, L., Hang, M., Pergament, S., \& Pratt, R. (2016). They just respect you for who you are: contributors to educator positive youth development promotion for Somali, Latino, and Hmong students. Journal of Primary Prevention, 37(1), 71-86.

Allen, K., Kern, M. L., Vella-Brodrick, D., Hattie, J., \& Waters, L. (2018). What schools need to know about fostering school belonging: a meta-analysis. Educational Psychology Review, 30(1), 1-34.

García-Moya, I., Brooks, F., Morgan, A., \& Moreno, C. (2015). Subjective well-being in adolescence and teacher connectedness. A health asset analysis. Health Education Journal, 74(6), 641-654.

García-Moya, I., Bunn, F., Jiménez-Iglesias, A., Paniagua, C., \& Brooks, F. (2018). The conceptualization of school and teacher connectedness in adolescent research: A scoping review of literature. Educational Review. https://doi.org/10.1080/00131911.2018.1424117

Baumeister, R. F., \& Leary, M. R. (1995). The need to belong: desire for interpersonal attachments as a fundamental human motivation. Psychological Bulletin, 117(3), 497-529.

Braun, V., \& Clarke, V. (2013). Successful qualitative research. London: Sage.

Carr, D. (2005). Personal and interpersonal relationships in education and teaching: a virtue ethical perspective. British Journal of Educational Studies, 53(3), 255-271.

Chhuon, V., \& Wallace, T. L. (2014). Creating connectedness through being known: fulfilling the need to belong in U.S. high schools. Youth \& Society, 46(3), 379-401.

Clarke, V., Braun, V., \& Hayfield, N. (2015). Thematic analysis. In J. A. Smith (Ed.), Qualitative psychology (3rd ed., pp. 222-248). London: Sage.

Darling, N., Hamilton, S. F., \& Hames, K. (2003). Relationships outside the family: unrelated adults. In G. R. Adams \& M. D. Berzonsky (Eds.), Blackwell handbook of adolescence (pp. 249-370). Malden, MA: Blackwell Publishing.

Eccles, J. S., \& Roeser, R. W. (2009). Schools, academic motivation and stage-environment fit. In R. M. Lerner \& L. Steinberg (Eds.), Handbook of adolescent psychology (Vol. 1, pp. 404 434). Hoboken, NJ: John Wiley \& Sons.

Eccles, J. S., Midgley, C., Wigfield, A., Buchanan, C. M., Reuman, D., Flanagan, C., \& Mac Iver, D. (1993). Development during adolescence: the impact of stage-environment fit on young adolescents' experiences in schools and in families. American Psychologist, 48(2), 90-101.

Erickson, L. D., McDonald, S., \& Elder, G. H. (2009). Informal mentors and education: complementary or compensatory resources? Sociology of Education, 82(4), 344-367.

Garner, P. W. (2010). Emotional competence and its influences on teaching and learning. Educational Psychology Review, 22(3), 297-321.

Hargreaves, A. (2000). Mixed emotions: teachers' perceptions of their interactions with students. Teaching and Teacher Education, 16(8), 811-826.

Hülsheger, U. R., \& Schewe, A. F. (2011). On the costs and benefits of emotional labor: a meta-analysis of three decades of research. Journal of Occupational Health Psychology, 16(3), 361-389.

Karcher, M. J., \& Lee, Y. (2002). Connectedness among Taiwanese middle school students: a validation study of the Hemingway Measure of Adolescent Connectedness. Asia Pacific Education Review, 3(1), 92-114.

Klem, A. M., \& Connell, J. P. (2004). Relationships matter: linking teacher support to student engagement and achievement. Journal of School Health, 74(7), 262-273.

Koehler, A. A., Newby, T. J., \& Besser, E. D. (2016). In the eye of the beholder: using student narratives to explore memorable teachers. Educational Review, 69(2), 158-180.

Macleod, G., MacAllister, J., \& Pirrie, A. (2012). Towards a broader understanding of authority in studentteacher relationships. Oxford Review of Education, 38(4), 493-508.

Masten, A. S. (2001). Ordinary magic. Resilience processes in development. American Psychologist, 56(3), $227-238$.

Mesquita, B., \& Frijda, N. H. (1992). Cultural variations in emotions: a review. Psychological Bulletin, 112(2), 179-204.

Monks, C. P., Ortega-Ruiz, R., \& Rodríguez-Hidalgo, A. J. (2008). Peer victimization in multicultural schools in Spain and England. European Journal of Developmental Psychology, 5(4), 507-535.

OECD. (2017). Results from PISA 2015 student's wellbeing. Country notes. http://www.oecd. org/education/pisa-2015-results-volume-iii-9789264273856-en.htm. Accessed 24 Jan 2019

Pirrie, A., \& Rafanell, I. (2017). Re-conceptualising authority relations in education: a micro-situational approach. Critical Studies in Education. Advanced online publication. https://doi.org/10.1080/17508487.2017.1343198.

Reddy, R., Rhodes, J. E., \& Mulhall, P. (2003). The influence of teacher support on student adjustment in the middle school years: a latent growth curve study. Development and Psychopathology, 15(1), 119-138.

Reed, D. K., \& Wexler, J. (2014). "Our teachers...don't give us no help, no nothin": Juvenile offenders perceptions of academic support. Residential Treatment for Children \&Youth, 31(3), 188-218.

Roorda, D. L., Koomen, H. L., Spilt, J. L., \& Oort, F. J. (2011). The influence of affective teacher-student relationships on students' school engagement and achievement: a meta-analytic approach. Review of Educational Research, 81(4), 493-529. 
Sass, D. A., Castro-Villarreal, F., McWhirter, B. T., McWhirter, E. H., \& Karcher, M. J. (2011). A cross-cultural assessment of school connectedness: Testing measurement invariance with United States and Chilean adolescents. Journal of Psychoeducational Assessment, 29(5), 428-442.

Shank, G., \& Villella, O. (2004). Building on new foundations: core principles and new directions for qualitative research. The Journal of Educational Research, 98(1), 46-55.

Steinberg, L. (2001). We know some things. parent-adolescent relationships in retrospect and prospect. Journal of Research on Adolescence, 11(1), 1-19.

Suldo, S. M., Friedrich, A. A., White, T., Farmer, J., Minch, D., \& Michalowski, J. (2009). Teacher support and adolescents' subjective well-being: a mixed-methods investigation. School Psychology Review, 38(1), 67-85.

Townsend, K. C., \& McWhirter, B. T. (2005). Connectedness: a review of the literature with implications for counseling, assessment, and research. Journal of Counseling \& Development, 83(2), 191-201.

Wrong, D. (2009). Power: its forms, bases and uses. New Jersey: Transaction Publishers, Routledge.

Yu, M. V. B., Johnson, H. E., Deutsch, N. L., \& Varga, S. M. (2018). "She calls me by my last name": exploring adolescent perceptions of positive teacher-student relationships. Journal of Adolescent Research, 33(3), 332362.

Zhu, C. (2013). Students and teachers thinking styles and preferred teacher interpersonal behaviour. Journal of Educational Research, 106(5), 399-407.

Irene García-Moya. CRIPACC, School of Health and Social Work, University of Hertfordshire, College Lane Campus, Hatfield, Hertfordshire AL10 9AB, UK; Department of Developmental and Educational Psychology, University of Seville, C/ Camilo José Cela s/n 41018 Seville, Spain. E-mail: i.garciamoya2@herts.ac.uk

Current themes of research:

School experiences. Student-teacher relationships and well-being. Schools and family as key educational contexts in adolescence.

Most relevant publications in the field of Psychology of Education:

García-Moya, I., Bunn, F., Jiménez-Iglesias, A., Paniagua, C., \& Brooks, F. (2018). The conceptualization of school and teacher connectedness in adolescent research: A scoping review of literature. Educational Review. doi: 10.1080/00131911.2018.1424117

García-Moya, I., Brooks, F., \& Spencer, N. (2018) School-level factors associated with teacher connectedness: A multilevel analysis of the structural and relational school determinants of young people's health. Journal of Public Health, 40(2), 366-374. doi: 10.1093/pubmed/fdx089

García-Moya, I., Jiménez-Iglesias, A. \& Moreno, C. (2017) The contribution from relationships with parents and teachers to the adolescent sense of coherence (SOC). Do prosociality and hyperactivity-inattention also play a significant role? Young, 25(4) 391-406. doi: 10.1177/1103308816646672

Sánchez-Queija, I., García-Moya, I. \& Moreno, C. (2017). Trend analysis of bullying victimization prevalence in Spanish adolescent youth at school. Journal of School Health 87(6), 457-464. doi:10.1111/josh.12513

García-Moya, I., Brooks, F., Morgan, A., \& Moreno, C. (2015). Subjective well-being in adolescence and teacher connectedness. A health asset analysis. Health Education Journal, 74(6), 641-654. doi: 10.1177/ 0017896914555039

Fiona Brooks. Faculty of Health, University of Technology Sydney, PO Box 123 Broadway, Sydney NSW 2007, Australia; CRIPACC, School of Health and Social Work, University of Hertfordshire, College Lane Campus, Hatfield, Hertfordshire AL10 9AB, UK. E-mail: fiona.brooks@uts.edu.au

Current themes of research:

Determinants of young people's health and well-being. Study of health assets for young people. Adolescents' and children's voices in health encounters. 
Most relevant publications in the field of Psychology of Education:

García-Moya, I., Bunn, F., Jiménez-Iglesias, A., Paniagua, C., \& Brooks, F. (2018). The conceptualization of school and teacher connectedness in adolescent research: A scoping review of literature. Educational Review. doi: 10.1080/00131911.2018.1424117

García-Moya, I., Brooks, F., \& Spencer, N. (2018) School-level factors associated with teacher connectedness: A multilevel analysis of the structural and relational school determinants of young people's health. Journal of Public Health, 40(2), 366-374. doi: 10.1093/pubmed/fdx089

García-Moya, I., Brooks, F., Morgan, A., \& Moreno, C. (2015). Subjective well-being in adolescence and teacher connectedness. A health asset analysis. Health Education Journal, 74(6), 641-654. doi: 10.1177/ 0017896914555039

Carmen Moreno. Department of Developmental and Educational Psychology, University of Seville, C/Camilo José Cela s/n 41018 Seville, Spain. E-mail: mcmoreno@us.es

Current themes of research:

Study of children's and adolescents' development within educational contexts. Analysis of risk and protective factors for positive development in childhood and adolescence.

Most relevant publications in the field of Psychology of Education:

García-Moya, I., Jiménez-Iglesias, A. \& Moreno, C. (2017) The contribution from relationships with parents and teachers to the adolescent sense of coherence (SOC). Do prosociality and hyperactivity-inattention also play a significant role? Young, 25(4) 391-406. doi: 10.1177/1103308816646672

Sánchez-Queija, I., García-Moya, I. \& Moreno, C. (2017). Trend analysis of bullying victimization prevalence in Spanish adolescent youth at school. Journal of School Health 87(6), 457-464. doi:10.1111/josh.12513

García-Moya, I., Brooks, F., Morgan, A., \& Moreno, C. (2015). Subjective well-being in adolescence and teacher connectedness. A health asset analysis. Health Education Journal, 74(6), 641-654. doi: 10.1177/ 0017896914555039

\section{Affiliations}

\section{Irene García-Moya $^{1,2} \cdot$ Fiona Brooks ${ }^{1,3} \cdot{\text { Carmen } \text { Moreno }^{2}}^{2}$}

Fiona Brooks

fiona.brooks@uts.edu.au

Carmen Moreno

mcmoreno@us.es

1 CRIPACC, School of Health and Social Work, University of Hertfordshire, College Lane Campus, Hatfield, Hertfordshire AL10 9AB, UK

2 Department of Developmental and Educational Psychology, University of Seville, C/ Camilo José Cela s/n, 41018 Seville, Spain

3 Faculty of Health, University of Technology Sydney, PO Box 123 Broadway, Sydney, NSW 2007, Australia 